4. Smartt, S. J. Annu. Rev. Astron. Astrophys. 47, 63-106 (2009)

5. Kasen, D., Röpke, F. K. \& Woosley, S.E. Nature $\mathbf{4 6 0}$ 869-872 (2009)

6. Law, N. M. et al. Publ. Astron. Soc. Pacif. 121, 1395-1408 (2009).

\title{
GLOBAL CHANGE
}

\section{The ocean is warming, isn't it?}

\author{
Kevin E. Trenberth
}

\section{A reappraisal of the messy data on upper-ocean heat content for 1993-2008 provides clear evidence for warming. But differences among various analyses and inconsistencies with other indicators merit attention.}

Global atmospheric temperatures at Earth's surface are often taken as an indicator of global warming. Yet the atmosphere is battered by all sorts of natural variability associated with weather phenomena. More robust indicators of a warming planet come from evidence of increasing ocean heat content and associated sea-level rise. Yet observing systems that capitalize on these insights are in their infancy. On page 334 of this issue, a step forward is reported by Lyman et al. ${ }^{1}$ - they find a robust warming of the global upper ocean to be present in the data, in spite of considerable uncertainties arising from the observations themselves.

In September 2009 a meeting $^{2}$ called OceanObs'09, involving more than 600 scientists from 36 nations, took place in Venice and focused on progress in observing the ocean since the Initial Oceanobserving System was mooted a decade earlier at the OceanObs'99 conference. The participants not only assessed the revolutionary advances that have taken place in ocean observations, but also considered how the observations, their processing and their translation into useful information for decisionmakers should progress into the future.

The revolution has been brought about by two major developments. The first is millimetre-precision altimetry from satellites to give sea level globally since 1992; the second is the Argo profiling float system of nominally 3,000 floats that provide vertical profiles of temperature and salinity over the upper 2,000 metres of the ocean every 10 days or so. The latter has been built up to approach global coverage and the nominal numbers since about 2003. Before then, the bulk of the observations of the ocean were from expendable bathythermographs (XBTs) dropped from ships along their tracks as opportunities arose. As a result, coverage was spotty and irregular, and missing over many regions such as the Southern
7. Drake, A. J. et al. Astrophys. J. 696, 870-884 (2009).

8. Young, D. R. et al. Astron. Astrophys. 489, 359-375 (2008).

9. Lien, A. \& Fields, B. D. J. Cosmol. Astroparticle Phys. 1, 047 (2009).
Ocean. The XBTs recorded temperatures, but their depths were estimated on the basis of an assigned drop rate, which turned out to be sensitive to the exact design and character of the XBT probe. Recent careful comparisons with calibrated probes deployed from research vessels have shown the need for corrections ${ }^{3}$.

The severe under-sampling of the ocean results. They perform a detailed error analysis that helps determine the confidence in the results and where improvements can be made. Their conclusions provide a valuable caution for users of these data.

In spite of all the difficulties, Lyman et al. are able to demonstrate a robust warming of the global upper ocean from 1993 to 2008, depicted by the red line in Figure 1, which averages $0.64 \pm 0.29$ watts per square metre $(95 \%$ confidence interval) for the Earth as a whole. This is reasonably consistent with expectations from other indications of global warming ${ }^{6}$. Nonetheless, the results reveal that all curves flatten out after 2003 (as seen in the black line in Fig. 1; see also ref. 7 , for example), suggesting that ocean warming has stalled. However, independent analysis $^{8}$ of the full-depth Argo floats for 2003 to 2008 suggests that the 6-year heat-content increase is $0.77 \pm 0.11 \mathrm{~W} \mathrm{~m}^{-2}$ for the global ocean or $0.54 \mathrm{~W} \mathrm{~m}^{-2}$ for the entire Earth, indicating that substantial warming may be taking place below the upper $700 \mathrm{~m}$ (Fig. 1, blue line).

Although Lyman and colleagues' paper reinforces the overall view that the ocean has been warming at a rate consistent with radiative imbalance estimates from anthropogenic climate change, the slowdown since 2003 is at odds with top-of-atmosphere radiation measurements'. This discrepancy suggests that further problems may be hidden within the ocean observations and their processing. It also highlights the need to do better, and the prospects for that. Experience in the atmosphere has long highlighted the desirability of working with 'anomalies' as departures from a well-established climatology. Moreover, methods of analysis and interpolation of gaps in space and time should take account of the warming climate, and care is needed not to bias results towards background values. As the relevant analytical methods mature, ocean heat ntil about five years ago, along with the variety of methods used to correct for problems and biases, has led to many estimates of how the temperatures in the ocean have changed over time. Of particular interest for climate is the vertically integrated ocean heat content. The reprocessing of XBT and Argo observations has resolved some issues highlighted in the last report of the Intergovernmental Panel on Climate Change (IPCC $)^{4}$, in which inflated decadal variability was evidently due to changes over time in XBT design, deployment and data analysis ${ }^{5}$. But there remains a surprisingly large spread among different estimates of ocean heat content.

Lyman et al. ${ }^{1}$ delve into the origins of these differences, and compile and reprocess a common data set for the upper $700 \mathrm{~m}$ of the ocean to isolate how various assumptions affect the content is likely to become a key indicator of climate change.

Kevin E. Trenberth is at the National Center for Atmospheric Research, PO Box 3000, Boulder,

Colorado 80307, USA.

e-mail: trenbert@ucar.edu

1. Lyman, J. M. et al. Nature 465, 334-337 (2010).

2. Harrison, D. E. \& Legler, D. M. Eos 91, 23 (2010).

3. Gouretski, V. \& Koltermann, K. P. Geophys. Res. Lett. 34, L01610, doi:10.1029/2006GL027834 (2007).

4. Bindoff, N. L. et al. in Climate Change 2007: The Physical Science Basis (eds Solomon, S. et al.) 385-428 (Cambridge Univ. Press, 2007)

5. Domingues, C. M. et al. Nature 453, 1090-1093 (2008)

6. Trenberth, K. E., Fasullo, J. T. \& Kiehl, J. Bull. Am. Meteorol. Soc. 90, 311-323 (2009)

7. Levitus, S. et al. Geophys. Res. Lett. 36, L07608, doi:10.1029/2008GL037155 (2009)

8. von Schuckmann, K., Gaillard, F. \& Le Traon, P.-Y. J. Geophys. Res. 114, C09007, doi:10.1029/2008JC005237 (2009).

9. Trenberth, K. E. \& Fasullo, J. T. Science 328, 316-317 (2010) 